\title{
Reducing health care costs by rationalizing staffing in primary care settings
}

S. Mawajdeh, ${ }^{1}$ S.A. Khoury, ${ }^{2}$ R. Yoder ${ }^{3}$ and M. Qtaishat ${ }^{4}$

$$
\begin{aligned}
& \text { تقليص تكاليف الرعاية الصحية بتزشيد تعيين الموظفين في مواقع الرعاية الصحية الأولية }
\end{aligned}
$$

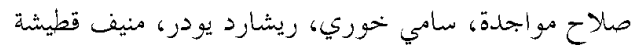

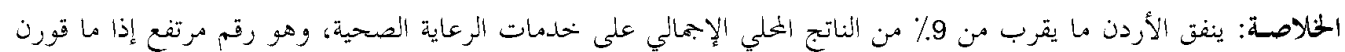

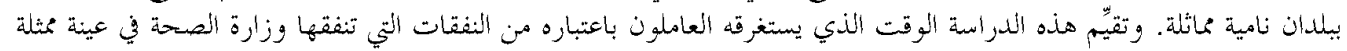

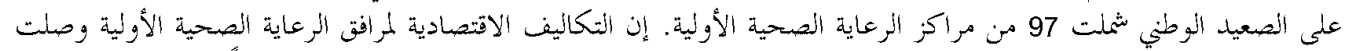

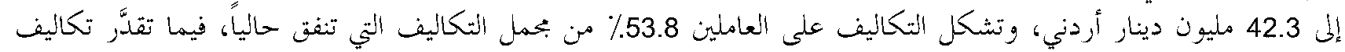

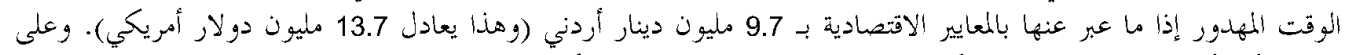

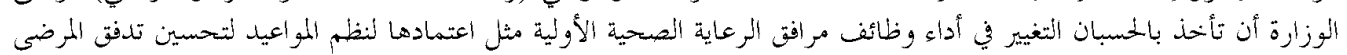

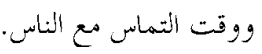

ABSTRACT Jordan spends around $9 \%$ of its GDP on health care services, a high figure compared with similar developing countries. This study assessed staffing patterns in relation to Ministry of Health expenditures in a nationally representative sample of 97 primary care facilities. The economic costs of primary care facilities amounted to Jordanian dinar (JD) 42.3 million. Personnel costs consumed $53.8 \%$ of recurrent costs and in monetary terms the amount of down time (time not being used effectively) amounted to JD 9.7 million (about US\$13.7 million). The Ministry should consider changing the functioning of its primary care facilities to obtain a more cost-effective use of staff time.

La réduction des coûts des soins de santé par la rationalisation des effectifs dans les établissements de soins de santé primaires

RESUME La Jordanie consacre environ $9 \%$ de son PIB aux services de soins de santé, un chiffre élevé par rapport à d'autres pays en développement similaires. On a étudié la dotation en personnel en rapport avec les dépenses du ministère de la Santé dans un échantillon national représentatif de 97 établissements de soins de santé primaires. Les coûts économiques des établissements de soins de santé primaires s'élevaient à JOD 42,3 millions. Les dépenses de personnel ont absorbé 53,8 \% des coûts de fonctionnement et le montant correspondant au temps d'inactivité (temps qui n'est pas utilisé effectivement) en termes monétaires s'élevait à JOD 9,7 millions (environ USD 13,7 millions). Le ministère devrait envisager de modifier le fonctionnement de ses établissements de soins de santé primaires pour une utilisation plus efficace du temps du personnel.

\footnotetext{
${ }^{1}$ Department of Health Policy and Management, Faculty of Medicine, Jordan University of Science and Technology, Irbid, Jordan.

${ }^{2}$ Department of Community Medicine; ${ }^{4}$ Department of Business Education, University of Jordan, Amman, Jordan.

${ }^{3}$ Department of Business and Economics, Eastern Mennonite University, Harrisonburg, Virginia, United States of America.

Received: 24/12/02; accepted: 31/03/03
}

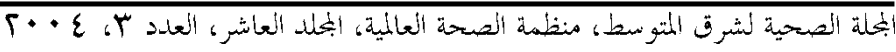




\section{Introduction}

In the light of continuing pressure, particularly external, to reduce the size of government budgets in low- and middle-income countries around the world, ministries of health are examining ways to increase efficiency and generate cost savings. Personnel costs typically consume the largest share of health ministry budgets, and consequently become a primary area of analysis.

Jordan, and its Ministry of Health $(\mathrm{MOH})$, is no exception to such pressure. According to the National Health Accounts estimates of 2000, Jordan spent approximately 454 million Jordanian dinar (JD) (US\$ 647 million) on health care services [1]. This amount represents $9.12 \%$ of the country's gross domestic product (GDP). Per capita health care expenditure amounted to approximately JD 94 (US\$132).

The breakdown of health expenditures by source of funds shows that $47 \%$ comes from private sources and $45 \%$ from public funds, with the remaining $8 \%$ contributed by international donors and other sources. Further breakdown of public health expenditure shows that preventive health services provided by primary care have a smaller proportion of the total health care budget (25\%) compared with the curative services (61\%); $5 \%$ of costs are administrative, $3 \%$ training and $6 \%$ miscellaneous.

There are several reasons why Jordan needs to re-examine its return in investment on the health of its citizens:

- Expenditure on health is already high when compared with other countries at the same level of socioeconomic development.

- There is a mismatch between population growth and economic growth, which has been declining over the past
5 years, thus leading to falling per capita incomes and lower standards of living.

- There is an increase in the proportion of elderly people in the total population, which is expected to put more pressure on the health care system.

- The country lacks a 'cost containment culture'. Ministries providing services plan their budgets based on historical experience where past budgets and expenditures tend to guide future plans. There is also an incentive to spend allocated budgets because unspent funds are reimbursed to the Ministry of Finance at the end of the fiscal year and not back to the $\mathrm{MOH}$.

- There is a wide variation in the quality of services provided by an overloaded public sector and mainly unregulated private health care [2].

The ministries of health in developing countries share many common problems, notably the presence of excess service capacity at various levels of care. This excess service capacity translates into a significant proportion of ministry of health budgets being allocated to personnel.

Health sector reform has been occurring in countries throughout the world for many years and is constantly undergoing change [3]. However, the central goals remain focused on improving access, equity, quality, efficiency, and/or sustainability. In order to achieve these health sector reform attributes, the need for development of national strategies for human resources becomes more important than ever [4].

A national study in Jordan aimed to study staffing patterns and utilization of time by health care providers and relate these to the cost of providing health services. We have already reported an analysis of staff performance in primary health care services [5]. This paper examines staffing

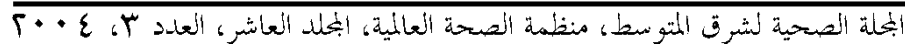


patterns and estimates the cost savings of providing primary health care services in a more efficient manner.

\section{Methods}

\section{Sample}

The study was carried out in 2001. A complete list of primary health care facilities was obtained from the $\mathrm{MOH}$, which also included the type of facilities and the numbers and types of staff (physicians, nurses and midwives) as well as the total number of patients seen in a year at each facility. The study sample was selected from 631 facilities of different types throughout Jordan: 42 comprehensive (CHCs), 336 primary health care centres (PHCs) and 253 village health centres (VHCs).

Facilities were categorized into low, medium and high volume groups, based on the 33rd and 66th percentiles of the number of annual visits. Since the study had several components, the variance of which is unknown in the study population, it was judged that a proportion of 0.5 would yield the largest sample size. The study sample was selected in a simple random fashion using SPSS version 7.5. Selection of the sample was proportional to size within each selection category (type of facility and volume). A confidence limit of $95 \%$ and a precision of $10 \%$ were used. The number of facilities selected in this manner was 99. Facilities were excluded from the study if they were being closed down or served a special population group, such as prisoners. The final sample at the end of fieldwork was 97 facilities comprising $8 \mathrm{CHCs}$, 50 PHCs and 39 VHCs.

\section{Data collection}

An exhaustive list of study instruments was prepared that recorded relevant facets of health services delivery at the primary health care level. These facets included, the type and quantity of personnel per facility, room dimensions, medical equipment, furniture, drugs, clinical supplies, non-clinical supplies, dental equipment, dental supplies, laboratory equipment, laboratory supplies, $\mathrm{X}$-ray equipment, X-ray supplies, number of patient visits by type of facility, utilities and prices of data items collected in the field. Data were collected using doctors, nurses, midwives, accountants and pharmacists.

\section{Data analysis}

In this study, economic cost was calculated so that all costs incurred in providing the service were considered, regardless of whether they were paid with government resources, subsidized or donated by local or international agencies. Moreover, opportunity cost was considered when estimating the annual cost of capital expenses.

Personnel costs were obtained from the personnel and accounting databases of the $\mathrm{MOH}$. For estimates of clinical supplies, consumption data was collected from the health facilities themselves and prices of items were obtained from the Central Purchasing Department.

For estimates of non-clinical supplies, data were obtained from the study health facilities. Allocation of items to the respective department was complicated since some of the items were used by some departments and not others, while some items were shared. Items were allocated to a particular department when it was clear which they belonged to (e.g. costs of X-ray envelopes were allocated to the X-ray department). Items such as detergents and cleaning materials were allocated to all service departments based on space shared in square metres.

Data about drug consumption were obtained from the study health facilities since

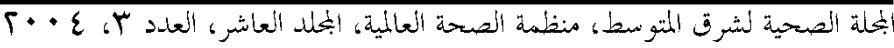


pharmacies are required by law to keep copies of prescriptions. Prescriptions were reviewed in order to obtain quantities used over a period. Tender prices were obtained from the central purchasing department.

We have reported in an earlier paper how activity sampling was used to measure providers' use of time and classify it into clinical time (activities when the provider was with a patient), non-clinical time (work-related, non-clinical activities) and down time (non-clinical, non-work related activities) [5]. To arrive at cost savings, the overall down time was multiplied by the cost of personnel. The respective down times for different types of facility and volume category were calculated.

\section{Results}

\section{Staffing patterns}

Out of the 8616 employees in MOH primary health care facilities, $1622(18.8 \%)$ were physicians, 2975 (34.5\%) nurses, 362 (4.2\%) midwives, $863(10.0 \%)$ support staff, and 2794 (32.4\%) administrative and others (Table 1).
PHCs employed the largest proportion $(63.3 \%)$ of health care professionals, followed by $\mathrm{CHCs}(28.1 \%)$ and VHCs (8.6\%). On average, a CHC facility had 58 employees, while a PHC had 16 employees and a VHC had about 3 employees. The ratio of staff varied by facility. For example in $\mathrm{CHC}$ facilities, there were 517 physicians and 706 nurses (a nurse:physician ratio of 1.37:1) compared with a nurse:physician ratio of 2.14:1 in PHCs.

During 1999, the total cost of providing primary health care services was JD 42.3 million. Recurrent costs represented $89 \%$, and the remaining $11 \%$ were capital costs. Personnel, as expected, represented the largest segment of the overall recurrent costs, where it amounted to JD 20.2 million, representing more than half $(53.8 \%)$ of recurrent costs (Table 2). The proportion of personnel costs out of total recurrent costs showed a wide variation by type of service. The lowest proportion was in dental services $(37.5 \%)$, and the highest in emergency services $(91.6 \%)$. The contribution of personnel costs to recurrent costs varied little by type of facility and volume of clients (Table 2).

\begin{tabular}{|c|c|c|c|c|c|c|c|}
\hline \multirow[t]{2}{*}{ Variable } & \multicolumn{6}{|c|}{ No. of staff } & \multirow[t]{2}{*}{$\%$} \\
\hline & Physicians & Nurses & Midwives & Support & Others & Total & \\
\hline \multicolumn{8}{|l|}{$\begin{array}{l}\text { Type of health care } \\
\text { facility }\end{array}$} \\
\hline Comprehensive & 517 & 706 & 76 & 334 & 788 & 2421 & 28.1 \\
\hline Primary care & 887 & 1896 & 286 & 506 & 1882 & 5457 & 63.3 \\
\hline Village & 218 & 373 & 0 & 23 & 124 & 738 & 8.6 \\
\hline \multicolumn{8}{|l|}{ Volume of clients } \\
\hline Low & 330 & 851 & 104 & 160 & 616 & 2061 & 23.9 \\
\hline Medium & 554 & 988 & 139 & 270 & 893 & 2844 & 33.0 \\
\hline High & 738 & 1136 & 119 & 433 & 1285 & 3711 & 43.1 \\
\hline Total & 1622 & 2975 & 362 & 863 & 2794 & 8616 & 100.0 \\
\hline
\end{tabular}

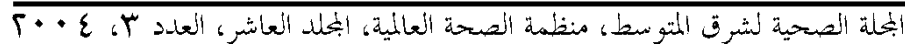




\section{Cost savings}

Based on data from our earlier paper [5] that down time among health providers was almost half their working time (48.7\%), estimates were made of the cost savings if down time was completely elim- inated (Table 3). The overall annual savings to the $\mathrm{MOH}$ in personnel cost was about JD 9.7 million and recurrent costs would go down from JD 37.6 million to JD 27.9 million $(26 \%)$. The change in cost savings ranged from $43.5 \%$ in specialty care to

Table 2 Distribution of personnel costs as a percentage of recurrent costs in different type of service by type of facility and volume of clients

\begin{tabular}{|c|c|c|c|c|c|c|}
\hline Variable & General & Specialty & Dental & Emergency & $\mathrm{MCH}$ & Total \\
\hline \multicolumn{7}{|l|}{ Type of health care facility } \\
\hline \multicolumn{7}{|l|}{ Comprehensive } \\
\hline Recurrent costs (JD) & 3694226 & 2208970 & 2942096 & 1379687 & 1146078 & 11371058 \\
\hline Personnel costs (JD) & 1693240 & 1433646 & 1191069 & 1174981 & 869140 & 6362077 \\
\hline Personnel costs (\%) & 45.8 & 64.9 & 40.5 & 84.9 & 75.8 & 55.9 \\
\hline \multicolumn{7}{|l|}{ Primary care } \\
\hline Recurrent costs (JD) & 12277705 & 22235 & 5765793 & 2346435 & 3633151 & 24045318 \\
\hline Personnel costs (JD) & 5244697 & 4893 & 2078424 & 2218398 & 3134518 & 12680930 \\
\hline Personnel costs (\%) & 42.7 & 22.0 & 36.0 & 94.5 & 86.3 & 52.7 \\
\hline \multicolumn{7}{|l|}{ Village $^{a}$} \\
\hline Recurrent costs (JD) & 1853374 & - & - & 296265 & 57888 & 2207527 \\
\hline Personnel costs (JD) & 868707 & - & - & 289842 & 35963 & 1194512 \\
\hline Personnel costs (\%) & 46.9 & - & - & 97.8 & 62.1 & 54.1 \\
\hline \multicolumn{7}{|l|}{ Volume of clients } \\
\hline \multicolumn{7}{|l|}{ Low } \\
\hline Recurrent costs (JD) & 3335728 & 81006 & 1602779 & 1114281 & 1126531 & 7260326 \\
\hline Personnel costs (JD) & 1471648 & 28561 & 706721 & 1039336 & 934651 & 4180917 \\
\hline Personnel costs (\%) & 44.1 & 35.3 & 44.1 & 93.3 & 83.0 & 57.6 \\
\hline \multicolumn{7}{|l|}{ Medium } \\
\hline Recurrent costs (JD) & 5582546 & 605611 & 2798517 & 1407999 & 1504205 & 11898878 \\
\hline Personnel costs (JD) & 2483528 & 333852 & 910064 & 1237277 & 1233253 & 6197975 \\
\hline Personnel costs (\%) & 44.5 & 55.1 & 32.5 & 87.9 & 82.0 & 52.1 \\
\hline \multicolumn{7}{|l|}{ High } \\
\hline Recurrent costs (JD) & 8907031 & 1544587 & 4306593 & 1500107 & 2206380 & 18464698 \\
\hline Personnel costs (JD) & 3851467 & 1076126 & 1652708 & 1406609 & 1871716 & 9858627 \\
\hline Personnel costs (\%) & 43.2 & 69.7 & 38.4 & 93.8 & 84.8 & 53.4 \\
\hline \multicolumn{7}{|l|}{ Total } \\
\hline Recurrent costs (JD) & 17825305 & 2231204 & 8707889 & 4022387 & 4837117 & 37623902 \\
\hline Personnel costs (JD) & 7806643 & 1438539 & 3269493 & 3683222 & 4039621 & 20237518 \\
\hline Personnel costs (\%) & 43.8 & 64.5 & 37.5 & 91.6 & 83.5 & 53.8 \\
\hline
\end{tabular}

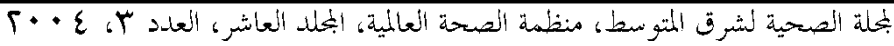


$48.7 \%$ in maternal and child health $(\mathrm{MCH})$ services. The largest annual cost saving (JD 3.8 million) was in general practice services, and the lowest (JD 626 087) was in specialty care.

\section{Discussion}

The Jordanian primary care system is reasonably robust and widespread. People who need care can access some basic care; more than $95 \%$ of Jordanians live within 10 $\mathrm{km}$ of a health facility. However, given the macro-economic trends and population growth rate, the ability to sustain even the existing level of quality and amount of services in the future may be a challenge.

In Jordan, the overall expenditure on primary health care is not very high, but there is room to improve how resources are allocated and the efficiency of their use. More than half of recurrent costs are accounted for by personnel in the form of salaries, incentives and allowances. This leaves service provision with relatively small amounts of money.
As reported earlier by Khoury and Mawajdeh [5] almost half of service providers' time in Jordanian primary care facilities is 'down time', i.e. waiting for patients, breaks and non-work related activities. The present paper attempted to examine from a purely economic point of view the hypothetical savings if systems were put in place to eliminate this down time. The results showed that financially such a move would save the MOH more than US\$ 13700000 each year. This excess money could be used to provide improved quality of care. Efficiency improvements could be made by, for example, closing underutilized facilities or reducing the size of the MOH payroll. However, a number of factors are expected to militate against this, the major obstacle being the current unemployment rate in the country of $15 \%$.

This paper also argues that the $\mathrm{MOH}$ ought to consider improving the functioning of its primary health care facilities. One of the first steps towards enhancing the quality of care would be to utilize the pro-

Table 3 Total recurrent costs, personnel cost and cost savings for different types of service before and after elimination of down time

\begin{tabular}{lrrrrrr}
\hline Service & \multicolumn{2}{c}{$\begin{array}{c}\text { Recurrent costs (JD) } \\
\text { Before }\end{array}$} & \multicolumn{1}{c}{ After } & \multicolumn{2}{c}{ Personnel costs (JD) } & \multicolumn{2}{c}{$\begin{array}{c}\text { Savings in } \\
\text { personnel }\end{array}$} & \% change \\
& & & & After & costs (JD) & \\
\hline General & 17825305 & 14038092 & 7806643 & 4019431 & 3787212 & -48.5 \\
Specialty & 2231204 & 1605118 & 1438539 & 812452 & 626087 & -43.5 \\
Dental & 8707889 & 7148484 & 3269493 & 1710088 & 1559405 & -47.7 \\
Emergency & 4022387 & 2258700 & 3683222 & 1919534 & 1763688 & -47.9 \\
MCH & 4837117 & 2871134 & 4039621 & 2073638 & 1965983 & -48.7 \\
Total & 37623902 & 27921526 & 20237518 & 10535142 & 9702376 & -47.9 \\
\hline
\end{tabular}

$J D=$ Jordanian dinar

$\mathrm{MCH}=$ maternal and child health.

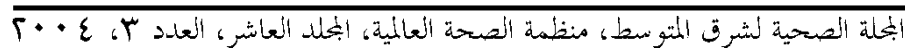


viders' time more effectively. This can be achieved by implementing a system that involves defining a suitable case-mix, and that requires firm control or incentives for service providers to be more detailed in their assessment and dispensing of care. At present patients of all types can be seen in the 3 types of $\mathrm{HC}$ and some form of referral centre should be adopted to channel patients to the appropriate level of health facility. Thus the case-mix in CHCs should be different from the less complex PHCs and the least complex VHCs.

Adoption of an appointment system in facilities where services are non-urgent (e.g. general practice, $\mathrm{MCH}$, family planning, dental and specialty clinics) could assist in better managing the patient flow by spreading clients throughout the day. Spreading the client load over a few extra hours could also lead to more time spent per client and therefore resolve to some extent the problem of excessive down time, and ensure higher quality care.
However, interventions would be needed to ensure that providers of care adapt their practice style to the increase in time allocated per client. Introducing standardized protocols and training for these, coupled with a simple management information system, would help to ensure that providers' time was used effectively. Computer simulations have been employed to improve outpatient clinic staffing, scheduling [6] and clinic efficiency [7]. Creative ideas are needed to keep primary health care services accessible and at the same time minimize daily fluctuations in utilization levels. Reilly el al. [8] used a delay-scheduling model for patients using walk-in clinics and a simulation model that was validated using actual data and was able to reduce manpower needs by $10 \%$ and reduce waiting time.

In summary, this study calls for a system-wide approach to improving efficiency and quality of care in the Jordanian primary health care system since many of the factors presented are interlinked.

\section{References}

1. Jordan national health accounts. Technical report no. 49. Bethesda, Maryland, Partnerships for Health Reform, 2000.

2. Hashemite Kingdom of Jordan: health sector study. (World Bank country study.) Washington, DC, World Bank, 1996.

3. Kutzin J. Experience with organizational and financing reform of the health sector. Current concerns. SHS paper no. 8. Geneva, World Health Organization, 1995. (SHS/CC/94.3).

4. Alwan A, Hornby P. The implications of heath sector reform for human resources development. Bulletin of the World Health Organization, 2002, 80(1):5660.

5. Khoury SA, Mawajdeh S. Performance of health providers in primary health care services in Jordan. Eastern Mediterranean health journal, 2004, 10(3):37887.

6. Hashimoto F, Bell S. Improving outpatient clinic staffing and scheduling with computer simulation. Journal of general internal medicine, 1996, 11(3):182-4.

7. Clague JE et al. Improving outpatient clinic efficiency using computer simulation. International journal of health care quality assurance incorporating leadership in health services, 1997, 10:197201.

8. Reilly TA, Marathe VP, Fries BE. A delayscheduling model for patients using a walk-in clinic. Journal of medical systems, 1978, 2(4):303-13.

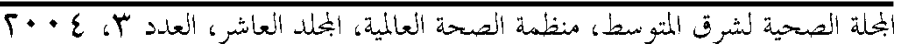

